\title{
Presentation
}

\section{Pay for Performance, Formulation, Implementation and Policy Success: in Low, Middle and High Income Countries ${ }^{1}$}

\author{
Fabiana da Cunha Saddi² \\ Visiting Lecturer at the Federal University of Goias, Goiânia, Goiás, Brazil \\ fabianasaddiı@gmail.com \\ Stephen Peckham \\ Professor of Health Policy at the University of Kent, Canterbury, UK \\ S.Peckham@kent.ac.uk \\ Pedro dos Santos Mundim \\ Associate Professor at the Federal University \\ of Goias, Goiânia, Goiás, Brazil \\ psmundim@gmail.com
}

Low and middle income countries (LMICs), as well as high income countries (HICs), with different political-economic contexts, varying dependence on external financing, as well as in differentiated stages of development of primary health care (PHC), have adopted payment for performance or performance-based financing programs $(\mathrm{P} 4 \mathrm{P} / \mathrm{PBF})$. Addressing the reality of different health systems and contexts, in LMICs and HICs, the rational-based assumptions supporting the design of $\mathrm{P} 4 \mathrm{P} / \mathrm{PBF}$ programmes have been theoretically questioned by more realistic political, organizational and motivational assumptions. Empirically, they have been challenged by alternative logics and processes arising from comparatively distinctive implementation and (re)formulation processes, diverse unexpected effects/ evidence and a recognition of the need to consider

1 We are grateful to Germano Coelho and Jaqueline Damasceno for their help in the edition of this introduction.

2 Fabiana da Cunha Saddi is a British Academy Newton Advanced Fellow, together with Stephen Peckham, and Visiting Research Fellow at the University of Kent. 
adaptations and long-term (sustainable) impacts on health systems. Consequently, P4P/ PBF programs have been subject to social sciences, public policy, health policy and health systems research. These analyses have the potential to significantly enrich the debate and knowledge on the operation and impact of $\mathrm{P} 4 \mathrm{P} / \mathrm{PBF}$ programs and how they could be more effectively designed to support health system performance and strengthening, producing effective/real-world or long-term improvements.

This special issue entitled "Pay for performance, formulation, implementation and policy success" includes papers from LMICs, as well as a translation of a paper about the Quality and Outcomes Framework (QOF) adopted in England/United Kingdom. This issue brings together the Brazilian and international knowledge about $\mathrm{P} 4 \mathrm{P} / \mathrm{PBF}$, being firstly (but not only) motivated by a relevant gap in the Brazilian literature regarding the National Programme for Improving Primary Care Access and Quality (PMAQ), which are predominantly quantitative, using official data (SADDI; PECKHAM, 2018). Given the wide variety of programs in HICs and LMICs with individual countries designing and implementing programs the discussion in this issue of the journal provides an opportunity for comparative assessment of programs.

$\mathrm{P} 4 \mathrm{P} / \mathrm{PBF}$ programs can be broadly defined as a mechanism through which health providers can be partially financed and/or health professionals receive financial incentives based on their performance. In most low-income countries (LICs), P4P programs are known as performance-based financing $(\mathrm{PBF})$. They require the execution of contracts with health units already in operation under the responsibility of governments. The PBF, in its initial phase - or generation - is not yet included as part of the national reform of the country's health system. The PBF was designed by a group of experts (FRITSCHE; SOETERS; MEESSEN, 2014), originated in Cambodia, being subsequently incorporated by the World Bank and other funding agencies who began to support the program at the time the program was being launched in Africa.

In a middle-income country, such as Brazil, the PMAQ is a national program, prepared by the formulators of the Department of Basic Attention of the Ministry of Health. It began in the context of fiscal constriction when the need to improve the Family Health Strategy evaluation was necessary in order to guarantee and justify increased funding for basic care (SADDI; PÊGO, 2018). In the UK QOF formed part of a new national contract for GPs introduced in 2004 as a response to years of underinvestment in general practice compared with other parts of the health service, low morale among GPs, and variations in the quality of primary medical care. While it was voluntary to participate the vast majority of practices took up the opportunity for additional income. Common to most schemes/countries is a focus on improving primary health care, ensuring comparable national, regional and local standards of quality. In LMICs they also aim to improve access to services. In LICs, they can also target the reconstruction of health systems or improvement of epidemic or basic health indicators.

Brazil and African countries have, or are, developing community-oriented primary care, working with health teams composed of doctors, nurses and community health 
workers $(\mathrm{CHW})$. In African countries, there is a range of integration of $\mathrm{CHW}$ into their health services - even though the involvement of $\mathrm{CHW}$ is considered an important driver in the implementation of PBF and PHC, as happened in Rwanda. In Brazil, where the development of a community model in PHC is more advanced, given the expansion of Family Health Strategy (FHS) in the country, PMAQ/P4P has not successfully managed to include the work of CHW during its implementation (SADDI et al., 2017 and 2018). In England, the QOF is linked to the work of the general practitioner and their contracted services.

With respect to the formulation and design process, $\mathrm{P} 4 \mathrm{P} / \mathrm{PBF}$ is still poorly studied around the world. In LICs, this is possibly because the formulation does not initially occur in the country or is not led by the government. A study carried out in 12 countries presents some facilities and barriers to progress towards the national adoption and institutionalization phases of the PBF (SHROFF, BIGDELI; MEESSEN, 2017). Systematic review and analysis, although in different ways, either draw attention to the need to take into account the contexts and design (EIJKENAAR, 2013; PAUL et al., 2018; RENMANS et al., 2016), or give emphasis to varied actors and relations and questions that frame the national ownership of the program and can influence its formulation (GAUTIER; RIDDE, 2017). All of them focus on the role that needs to be played by national actors.

In the Brazilian case, we know that the programme was discussed between formulators and members of health councils, and that they reached a consensus in order to have its approval by the Three-parties Health Commission (SADDI; PÊGO, 2018). However we do not yet know in a more analytical and in-depth way, how the PMAQ formulation/(re)design process occurred in its different rounds, and how national actors - researchers, council members and other - and few international experts have been involved in formulating and influencing its design. In England various analyses and commentaries by academic researchers, consultancies, health professional pressure groups, and committees have been examining the impact and process of the QOF. Recent research studies (FORBES; MARCHAND; PECKHAM, 2016; GRUTHRIE;TANG, 2016), and an NHS analysis (NATIONAL HEALTH SYSTEM ENGLAND, 2018), question the value and the future continuation of the program. Even though, we have not yet located a study focused on the policymaking process of QOF since 2004.

Regarding the implementation, themes such as organizational capacity, staff engagement, professional motivations, stress and work overload are also extensively considered in both HIC (GRUTHRIE; TANG, 2016; PECKHAM, 2007) and LMICs (EIJKENAAR, 2013; RENMANS et al, 2016; SADDI et al, 2018; TOONEN et al., 2009). Though in varied ways between LMI and HI countries, researchers/analyses have taken unintended consequences into account, such as gaming and cheating in Brazil (SADDI et al., 2017), perverse effects in African countries (PAUL et al., 2018), and Bureaucratisation, clinical autonomy and professionalism, crowding out and gaming in the UK (GRUTHRIE;TANG, 2016). 
Considering that $\mathrm{P} 4 \mathrm{P} / \mathrm{PBF}$ is focused mainly or only on a group of quality criteria and indicators that can be easily measured, researches have also been questioning the ways that policy impact and success have been measured and prevalent in the literature. Though in diverse ways, researchers from both HIC (PECKHAM; WALLACE, 2010) and LMICs have questioned whether P4P/PBF has affected health workers and local health organisations and whether it has affected the quality of the activities incentivised, areas not targeted by the program or the overall quality of primary care. Evidence in terms of PBF effectiveness and efficiency is mixed among countries, researchers have either shown or analytically stressed the fact that there is no evidence that PBF is a pro-poor strategy and that it would need equity targets (SKILLES et al., 2013). This refers to an emergent consensus in LICs (RIDDE et al., 2018) and an incipient debate related to the PMAQ in Brazil. In LICs analysis/debate also takes place either around the need to rethink the scheme (PAUL et al., 2018), or as a strategy/tool catalyst towards comprehensive health reform (FRITSCHE; SOETERS; MEESSEN, 2014) or that can move towards its institutionalization in health systems and depending on barriers/ facilitators (SHROFF; BIGDELI; MEESSEN, 2017). Evidence from the early years of the QOF suggested it reduced variations between practices in the delivery of incentivised interventions, and contributed to progress towards better use of electronic records and nurse-led multidisciplinary care of long-term conditions. However, after the first year of the QOF, most practices achieved near-maximum remuneration from the scheme raising questions about its value and each year adjustments were made to the measures with many now "retired". More recently the scheme has been dropped in Scotland and there is increasing variation in its application in England with the possibility its use will be dropped nationwide although data on areas of care that were in QOF will continue to be monitored but not necessarily incentivised financially.

The papers included in this issue can be seen as relevant cases of the current state of knowledge of the different political-economic contexts. Pierre Abomo, in his discussion paper, draws attention to the fact that the PBF literature has not yet sufficiently explored the implications for the ideological and operational changes that the PBF is causing. $\mathrm{He}$ introduces the concept of "depoliticization" in the PBF debate in Africa, and in particular in the case of Cameroon, to describe the capacity of PBF to redesign a health policy. His analysis takes into account not only political and state intervention, but also the primacy of the public sector in relation to the market competition field where the sponsored Government and non-state actors are located. The author recommends that PBF should be rethought in relation to its design, introduction and implementation, incorporating national actors in the design of the tool and definition of objectives and indicators. $\mathrm{He}$ argues that PBF, as proposed by external actors, needs to be immersed in the country's practice and formulation process.

Lara Gautier and Valéry Ridde, perform a documentary analysis of the World Bankadministrated Health Results Innovation Trust Fund (HRITF) learning agenda over ten years, when the impact evaluations of PBF pilot programs adopted in PRBM was 
predominant. The authors show that HRITF's productions/actions have produced both a form of politicized knowledge and a transformative use of knowledge in the area, given how both the design and evaluation of the pilot projects financed by the Fund took place. Authors highlight diverse learning activities have resulted in a transformative use of knowledge for World Bank staff, national policy makers and implementers, and recommend that the institution needs to move forward to become a transformative learning organization.

Larissa Lemos, Nília Prado and Maria Guadalupe Medina present a systematization of the concepts that frame the design of PMAQ/Brazil. This systematization highlights the logical plausibility of the proposal. It shows how new evaluations could focus on organizational issues, and make comparison between the program designed and its implementation in the municipalities. This work is politically relevant to the current state of knowledge of the PMAQ in Brazil, because it brings elements that will enable the development and deepening of questions regarding not only the implementation process, but especially the redesign and reformulation process of the program.

The paper by Jessica Gergen,Yogesh Rajkotia and Nirmala Ravishankar contribute to the debate about whether the PBF constitutes a mechanism capable of producing broad transformations in health systems. The authors use qualitative methods to analyse the implementation of PBF in health units, verifying how the PBF promoted positive, perverse and disruptive effects on the health system in two provinces of Mozambique. Among the positive results are the increase of the autonomy, local fiscal capacity and planning. Among the negative aspects, are the fact that the allocation of incentives among employees was unfair and without transparency, the increase in workload and time spent with data in the information system, in detriment of clinical care. The study shows that the persistence of positive results will depend on the institutionalization of changes in governance, management structures and fiscal autonomy, together with efforts to increase the inclusiveness of the demand-side.

Thabata Zermiani, Marcia Pinto and Rafael Ditterich conduct a qualitative and quantitative study to analyse the perception of health workers in Curitiba between 2002-2015, in Brazil, during the implementation of the Quality Development Incentive Program (IDQ), adopted by the Municipal Health Secretariat. Authors show that the incentive initially had positive results motivating health professionals, affecting the quality of work and achievement of goals. However, over time the evaluation became a routine, not being performed in the way it was theoretically advocated. The evaluation process, the prioritization of the quantity, the fraud of information to reach the goals and the fact that incentives were used as a manoeuvre to not increase the salaries were considered in the study as barriers to the implementation of the program. In the self-assessment, for example, professionals rarely gave a score below ten. Among the main lessons of the study, authors emphasize that performance programs should be transparent and impartial, promote dialogue between professionals and enable managers and professionals to appropriate all stages of agreement, so that there would be an effective impact on quality 
and results achieved. This study brings lessons that should be considered in the analysis of PMAQ and are in line with other few implementation studies about PMAQ.

Alline Orué, Albert Souza, Alcindo Ferla, Débora Nascimento and Mara Santos use official secondary data from the second round of PMAQ to analyse the implementation, planning and monitoring of the Family Health Support Center (NASF). Data showed that the NASF was implemented without proper articulation with PHC, centralized in management, mainly in capitals. It also showed that planning was organized, periodic and articulated.Authors point out that monitoring is still underdeveloped, with the exception of PMAQ, which induces activities through financial incentive and enables monitoring. This study exemplifies how the PMAQ data has been used around the country, and in various ways, to analyse or monitor processes related to Brazilian PHC, resulting in thousands and several works on Brazilian PHC. They are not, however, employed to analyse the proper implementation of the PMAQ or aspects strictly concerned with P4P themes.

Martin Roland and Frede Olesen in the article "Pay for Performance can improve the quality of primary health care?", originally published in the BMJ and translated into Portuguese in this issue, explore what other countries can learn from the Quality and Outcomes Framework (QOF) experience of the United Kingdom. The authors provide lessons on how quality of care has been and should be measured, and on who should decide which indicators to adopt. They also question the fact that physicians should not exclude patients because of program targets and thus question whether performance is the most helpful way to pay doctors. They also reflect on how often a P4P scheme should be reviewed and point out the role of unintended consequences to practitioners and formulators/ managers. These are themes that have characterized the adoption of QOF, but which are common to $\mathrm{P} 4 \mathrm{P} / \mathrm{PBF}$ in other parts of the globe, bringing light on the formulation and implementation processes in countries adopting community-based models in PHC.

The interview with James Macinko, carried out by Fabiana C. Saddi, systematizes the knowledge and opinion of a renowned scholar, shedding lights on processes and topics and politically relevant sub-themes at this stage of PMAQ in Brazil. Macinko talks about the origin and relevance of the PMAQ, as well as of incentive initiatives that preceded the program. He also answers questions about results produced to date, lessons learned/recommendations to move forward with PMAQ and risks that may arise from the introduction of $\mathrm{P} 4 \mathrm{P}$ into the national health system. Finally, the interviewee points out how the Brazilian Social Sciences could contribute to increase our knowledge about the PMAQ. Among the main sub-themes highlighted are the facts that municipalities with better resources may be able to earn incentive payments; the increase in data on PHC and its use for various purposes; the need to make the current method of data collection more transparent and independent, to better understand how incentive payments are actually being used and to communicate the work of the FHS to users and policymakers. 


\section{References}

EIJKENAAR, Frank. Effects of pay-for-performance in health care: a systematic review of systematic reviews. Pay-for-Performance for Healthcare Providers Design, performance measurement, and (unintended) effects. Netherlands: Het instituut Beleid \& Management Gezondheidszorg, 2013. Available from: <https://www.bmg.eur.nl/fileadmin/ASSETS/bmg/Onderzoek/Promoties/Promoties_2013/Frank_ Proefschrift.pdf>. Access on: 28 febr. 2018.

FORBES, Lindsay; MARCHAND, Catherine; PECKHAM, Stephen. Review of the Quality and Outcomes Framework in England: Final Report 2016. London: POLICY RESEARCH UNIT IN COMMISSIONING AND THE HEALTHCARE SYSTEM (PRUComm), 2016. 49 p. (Report). Available from: <http://blogs.lshtm.ac.uk/prucomm/files/2017/02/Review-of-QOF-21stDecember-2016.pdf>. Access on: 15 jan. 2017.

FRITSCHE, György Bèla;SOETERS, Robert; MEESSEN, Bruno. Performance-based financing toolkit. The World Bank, 2014. Available from: <https://openknowledge.worldbank.org/handle/10986/17194>. Access on: 12 febr. 2018.

GAUTIER, Lara; RIDDE, Valéry. Health financing policies in Sub-Saharan Africa: government ownership or donors' influence? A scoping review of policymaking processes. Global health research and policy, v. 2, n. 1, p. 23-39, 2017. Available from: <https://ghrp.biomedcentral.com/articles/10.1186/ s41256-017-0043-x>. Access on: 04 jan. 2018.

GUTHRIE, Bruce;TANG, Jason. What did we learn from 12 years of the Quality and Outcomes Framework?. Scottish School of Primary Care - Series Literature Review. September/2016. Available from: <http:// www.sspc.ac.uk/media/media_486342_en.pdf>.Access on: 23 may. 2018.

MEESSEN, Bruno; SOUCAT, Agnès; SEKABARAGA, Claude. Performance-based financing: just a donor fad or a catalyst towards comprehensive health-care reform?. Bull World Health Organ, v. 89, n. 2, p. 153-156, 2011. Available from: <https://www.ncbi.nlm.nih.gov/pubmed/21346927>. Access on: 04 mar. 2016.

NATIONAL HEALTH SYSTEM ENGLAND. Report of the Review of the Quality and Outcomes Framework in England. London: NHS England, 2018. 76 p. (Report). Available from: <https://www.england.nhs. $\mathrm{uk} /$ publication/report-of-the-review-of-the-quality-and-outcomes-framework-in-england/>. Access on: 20 sep. 2018.

PAUL, Elisabeth et al. Performance-based financing in low-income and middle-income countries: isn't it time for a rethink?. BMJ Global Health, v. 3, p. 1-7, 2018. Available from: <https://gh.bmj.com/ content/3/1/e000664>. Access on: 12 aug. 2018.

PECKHAM, Stephen. The new general practice contract and reform of primary care in the United Kingdom. Healthcare Policy, v. 2, n. 4, p. 34-48, 2007. Available from: <http://researchonline.lshtm. ac.uk/4933/1/Policy_vol2_no4_peckham.pdf>.Access on: 04 may. 2018.

PECKHAM, Stephen; WALLACE, Andrew. Pay for performance schemes in primary care: what have we learnt?. Quality in Primary Care, v. 18, n. 2, p. 111-116, 2010. Available from: <http://primarycare. imedpub.com/pay-for-performance-schemes-in-primary-care-what-have-we-learnt.php?aid=904>. Access on: 08 dec. 2015.

RENMANS, Dimitri et al. Opening the "black box" of performance-based financing in low-and lower middle-income countries: a review of the literature. Health Policy Planning, v. 31, n. 9, p. 1297-1309, 2016. Available from: <https://www.ncbi.nlm.nih.gov/pubmed/27126200>. Access on: 09 aug. 2018.

RIDDE, Valéry et al. Performance-based Financing in Africa: Time to Test Measures for Equity. International Journal of Health Services, v. 48, n. 3, p. 549-561, 2018. Available from: <https://www.ncbi. nlm.nih.gov/pubmed/29932352>. Access on: 22 sep. 2018. 
SADDI, Fabiana da Cunha et al. Perceptions and evaluations of front-line health workers regarding the Brazilian National Program for Improving Access and Quality to Primary Care (PMAQ): a mixedmethod approach. Cad. Saúde Pública, Rio de Janeiro, v. 34, n. 10, e00202417, 2018. Available from: $<$ http://www.scielo.br/scielo.php?script=sci_arttext\&pid=S0102-311X2018001005009\&lng=en\&nr $\mathrm{m}=$ iso $>$. Access on: 14 nov. 2018.

SADDI, Fabiana da Cunha et al. The politics of implementing a performance measurement program (PMAQ) at the front line of primary health care in Goiania, Brazil: a qualitative political analysis. In: International Conference on Public Policy, 3., 2017. Singapore. Anais... Singapore, 2017. p. 1-35. Available from: <http://www.ippapublicpolicy.org//file/paper/59a55b90e37cd.pdf>. Access on: 02 jan. 2018.

SADDI, Fabiana da Cunha; PECKHAM, Stephen. Brazilian Payment for Performance (PMAQ) Seen From a Global Health and Public Policy Perspective. Journal of Ambulatory Care Management, v. 41, n. 1, p. 25-33, 2018. Available from: <https://www.ncbi.nlm.nih.gov/pubmed/28990991>. Access on: 10 febr. 2018

SADDI, Fabiana da Cunha; PEGO, Raquel Abrantes. The collective health movement and health policy in Brazil: from regime transition/democratization to democracy and neoliberalism (1970s to 2014). Contextualizaciones Latinoamericanas, v. 10, n. 18, p. 2-11, 2018. Available from: <http://www. revistascientificas.udg.mx/index.php/CL/article/view/7254/6390>. Access on: 18 sep. 2018.

SHROFF, Zubin Cyrus; BIGDELI, Maryam; MEESSEN, Bruno. From Scheme to System (Part 2): Findings from Ten Countries on the Policy Evolution of Results-Based Financing in Health Systems. Health Systems \& Reform, v. 3, n. 2, p. 137-147, 2017. Available from: <https://www.tandfonline.com/ doi/abs/10.1080/23288604.2017.1304190>. Access on: 20 dec. 2017.

SKILES, Martha Priedeman et al. An equity analysis of performance-based financing in Rwanda: are services reaching the poorest women?. Health Policy and Planning, v. 28, n. 8, p. 825-837, 2013. Available from: <https://academic.oup.com/heapol/article/28/8/825/581934>. Access on: 12 apr. 2017.

TOONEN, Jurien et al. Learning lessons on implementing performance based financing, from a multi-country evaluation. KIT (Royal Tropical Institute) in collaboration with Cordaid and WHO, 2009. Available from: <http://www.who.int/contracting/PBF.pdf>. Access on: 07 apr. 2016. 